\title{
OVERVIEW OF THE DOE HYDROGEN SAFETY, CODES AND STANDARDS PROGRAM PART 2: HYDROGEN AND FUEL CELLS: EMPHASIZING SAFETY TO ENABLE COMMERCIALIZATION
}

\author{
N.F. Barilo ${ }^{1}$, S.C. Weiner ${ }^{2}$ and C. W. James ${ }^{3}$ \\ ${ }^{1}$ Pacific Northwest National Laboratory, Richland, WA 99354, USA, nick.barilo@pnnl.gov \\ ${ }^{2}$ Excelsior Design, Inc., Richland, WA, USA, sc.weiner@comcast.net \\ ${ }^{3}$ U.S. Department of Energy, Washington, DC, USA, charles.james@ee.doe.gov
}

\begin{abstract}
Safety is of paramount importance in all facets of the research, development, demonstration and deployment work of the U.S. Department of Energy's (DOE) Fuel Cell Technologies Program. The Safety, Codes and Standards sub-program (SC\&S) facilitates deployment and commercialization of fuel cell and hydrogen technologies by developing and disseminating information and knowledge resources for their safe use. A comprehensive safety management program utilizing the Hydrogen Safety Panel to raise safety consciousness at the project level and developing/disseminating a suite of safety knowledge resources is playing an integral role in DOE and SC\&S efforts. This paper provides examples of accomplishments achieved while reaching a growing and diverse set of stakeholders involved in research, development and demonstration; design and manufacturing; deployment and operations. The work of the Hydrogen Safety Panel highlights new knowledge and the insights gained through interaction with project teams. Various means of collaboration to enhance the value of the program's safety knowledge tools and training resources are illustrated and the direction of future initiatives to reinforce the commitment to safety is discussed.
\end{abstract}

\subsection{INTRODUCTION}

The central mission of the U.S. Department of Energy's Fuel Cell Technologies Program is to enable the widespread commercialization of a portfolio of hydrogen and fuel cell technologies through basic and applied research, technology development and demonstration, and diverse efforts to overcome institutional and market challenges. [1] A comprehensive R\&D and safety management program enables the Safety, Codes and Standards (SC\&S) sub-program to support this effort by

- Providing the scientific and technical basis for requirements in critical regulations, codes and standards to enable full deployment of hydrogen and fuel cell technologies in all market sectors and

- Developing and implementing practices and procedures for the safe conduct of DOEfunded hydrogen and fuel cell projects. [2]

The Hydrogen Safety Panel (HSP) plays an integral role in supporting the SC\&S program and raising safety consciousness directly at the project level. [3,4] Their body of expertise from the industrial, government and academic sectors has been broadly applied to emphasize the importance of priority and continuous attention to safety in all aspects of a broad project portfolio - research, technology development and market deployment.

The development and widespread sharing of accurate safety information and knowledge resources including lessons learned and best practices are also key objectives of the SC\&S program. [2] Their timely dissemination helps inform the work of codes and standards bodies as well as other key stakeholders in the hydrogen and fuel cell community. For example, hydrogen-related safety training resources developed for the R\&D community, code officials and first responders are available and can be utilized in a variety of formats. $[5,6]$ 
This paper provides examples of accomplishments achieved to address the needs and reach a growing and diverse set of stakeholders involved in research, development and demonstration; design and manufacturing; deployment and operations. The work of the Hydrogen Safety Panel is highlighted to emphasize how a wealth of historical experience, new knowledge and insights gained through engaged interaction with project teams has led to meaningful results. Various means of collaboration have been utilized to enhance the value of the developed safety knowledge tools and training resources and are illustrated in this paper.

\subsection{ENCOURAGING CONTINUOUS AND PRIORITY ATTENTION TO SAFETY}

The Hydrogen Safety Panel was formed in December 2003 to help DOE develop and implement practices and procedures that would ensure safety in the operation, handling and use of hydrogen and hydrogen systems for all DOE projects. Since that time, the core objectives of its work have remained essentially unchanged.

- Provide expertise and recommendations to DOE and assist with identifying safety-related technical data gaps, best practices and lessons learned.

- Help DOE integrate safety planning into funded projects to ensure that all projects address and incorporate hydrogen and related safety practices.

The HSP is comprised of 14 members having a broad cross-section of expertise from the commercial, industrial, government and academic sectors representing over 400 years of experience (see Table 1). Panel members participate in a variety of standards development organizations including the National Fire Protection Association, American Society for Mechanical Engineers (ASME), SAE International ${ }^{\circledR}$ and the International Organization for Standardization (ISO). They also contribute to peer-reviewed literature and trade magazines on hydrogen safety and present at national and international forums.

Table 1. Hydrogen Safety Panel Members (2016)

\begin{tabular}{ll}
\hline Name & Affiliation \\
\hline Nick Barilo, Manager & Pacific Northwest National Laboratory \\
\hline Bill Fort & Consultant \\
\hline David Farese & Air Products and Chemicals \\
\hline Larry Fluer & Fluer, Inc. \\
\hline Donald Frikken & Becht Engineering \\
\hline Aaron Harris & Air Liquide \\
\hline Richard Kallman, Chair & City of Santa Fe Springs, CA \\
\hline Chris LaFleur & Sandia National Laboratories \\
\hline Miguel Maes & NASA-JSC White Sands Test Facility \\
\hline Steve Mathison & Honda Motor Company \\
\hline Larry Moulthrop & Proton OnSite \\
\hline Glenn Scheffler & GWS Solutions of Tolland \\
\hline Steven Weiner & Excelsior Design, Inc. \\
\hline Robert Zalosh & Firexplo \\
\hline
\end{tabular}

The early work of the Panel focused on two principal activities: (1) the review of DOE-funded project safety plans [7] and (2) the conduct and reporting of project safety reviews conducted either onsite or 
via teleconferences. The requirement of the former is captured in a safety guidance document which the Panel updated most recently in 2010. [8] Although the safety plan is an early project deliverable, the Panel emphasizes that it be a living document focusing on the identification and analysis of safety vulnerabilities, the mitigation of associated risks, and assurances that effective safety communications plans are in place.

From the outset, project reviews conducted as site visits have focused on engagement and discussion between the Panel review team and the project team rather than as an audit or investigative exercise. Use of a review meeting protocol and an opportunity for the project team to respond to and document its responses to the Panel's recommendations in a final report have helped achieve a positive experience for all parties in the conduct of the safety review. Safety learnings from these early experiences have been shared broadly. [4,9] In total, the Panel has conducted over 400 project reviews that include safety plans, site visits, follow-up interviews and design review activities, and cover R\&D activities, vehicle fueling stations, and a range of early market fuel cell applications auxiliary power, backup power, combined heat and power, industrial truck fueling and portable power.

How do we measure the impact of the Panel's safety reviews of R\&D and demonstration projects alike? Those reviews have resulted in recommendations to more than 250 project teams that cover a range of topics:

- Safety vulnerabilities/mitigation analysis

- System/facility design modifications

- Equipment/hardware installation and O\&M
- Training

- Emergency response

- Safety documentation

Experience suggested that some recommendations were voluntarily completed even before the final safety review report was issued. Nonetheless, the consensus of the Panel suggested a need to establish a follow-up interview with project teams in order to identify actions, conclusions and findings as one means for measuring the value of this work as well as providing a rich source of safety-related experiences that could potentially have broader benefits to others. Ideally, recommendations should be tracked to final resolution. However, for the Panel's "point-in-time" interviews (i.e., 3-6 months after the final report was issued), over $90 \%$ of the recommendations had been voluntarily completed or were in progress, suggesting a meaningful effort to improve the safety aspects of the work being conducted. [10]

In later work, the HSP conducted safety reviews of deployment projects for industrial truck and backup power applications under the American Recovery and Reinvestment Act (ARRA). Follow-up interviews on safety review recommendations were conducted for three projects. In this case, only $56 \%$ of the referenced recommendations had been implemented or were in progress at the time of the interview. $[11,12]$ The ARRA results suggest that greater benefit could be derived for deployment projects particularly by engaging those teams earlier in their life cycle as safety planning and design are getting underway. This could include participation in early project design and document reviews, risk assessments, pre-startup reviews, and safety-focused site visits. One principal investigator summed this up by stating, "I believe getting the HSP involved early in the project contributes to a much safer outcome by putting many sets of highly qualified eyes on the project. In fact, it would have been useful to get the HSP involved even earlier in the design process - perhaps at the preliminary design review." [13] This approach encourages priority attention to safety and is now being formalized and implemented for application-focused projects.

Improvements and enhanced benefits are also being considered for HSP engagement with projects that are currently limited to safety plan reviews. HSP participation in an early safety planning (postkickoff) meeting to discuss expectations and what should be included in a good safety plan could yield significant value for the project. A post-plan review discussion with the project team of the Panel's recommendations could yield similar benefits. 
The HSP's early involvement in project activities should result in a greater impact on the project understanding of the safety issues and their significance, and help stakeholders to have a greater confidence in approving the project's final configuration.

\subsection{ADDRESSING KNOWLEDGE GAPS}

The Panel's involvement in a wide variety of early market demonstration projects puts it in a unique position to analyze issues and share what it has learned. The HSP has identified safety-related data gaps and produced white papers, recommendations and other documents to bring focused attention to a variety of technical issues. These have been made available to DOE and interested industry parties to better understand risks, identify safe practices and encourage the development of codes and standards.

A recent Panel white paper, "Safety of Hydrogen Systems Installed in Outdoor Enclosures," resulted from observations and considerations stemming from the Panel's work in support of DOE efforts to accelerate fuel cell commercialization in early market applications noted previously. [14] The paper focused on hydrogen system components installed in outdoor enclosures that can provide a space where a flammable mixture of hydrogen and air might accumulate; and proposed that a technical basis be developed to enable code bodies to write requirements for the range of enclosures from the smallest to the largest. The white paper and additional Panel efforts contributed to key changes for improving requirements in the 2016 edition of NFPA 2, "Hydrogen Technologies Code."

As another example, the HSP is currently developing a guide to assist code officials and project proponents with approval of hydrogen systems and facilities when listed equipment is not available. This effort is in response to a gap originally identified by the Panel during the ARRA project reviews that "third-party certification of all hydrogen and fuel cell equipment and systems deployed in these applications should be expeditiously sought and the impediments to using existing certification standards should be addressed and resolved." [15] The need for this initiative was also identified at a 2014 stakeholder meeting to consider the need for additional tools for supporting hydrogen and fuel cell commercialization. [16]

The challenge with certification is that the listing process for rapidly changing products, consistent with developing technologies, tends to be cost-prohibitive for equipment providers (each revision to the equipment requires recertification). Couple technologies under development with low demand for early market applications and the result is that few components and systems are currently listed. The scarcity of listed equipment places an extraordinary burden on code officials to ensure (and approve) that products include the appropriate inherent or automatic safety measures. The guide will identify listing requirements in the ICC codes and NFPA 2 for hydrogen equipment, and suggest criteria for approval when listed equipment is not available. This will provide common criteria for code officials and third parties to use in approving unlisted equipment. It will also level the playing field to ensure that different vendors are considering the same criteria across a variety of projects. A draft of the certification guide was made available in December 2015. [17]

With its broad expertise and substantial experience, the Hydrogen Safety Panel will continue to identify initiatives to bring focused attention, action, and outreach to bear on key safety issues for hydrogen and fuel cell technologies.

\subsection{ENGAGING STAKEHOLDERS}

Reaching, educating and informing stakeholders are critical for enabling the safe and timely deployment of hydrogen and fuel cell technologies. This is accomplished through direct engagement activities such as conducting HSP meetings, and developing tools for sharing information and knowledge through electronic media such as a web-based portal and mobile apps. 
The HSP holds one to two meetings per year to provide an opportunity to consider the results of recent project reviews, discuss timely safety issues, and engage stakeholders with the goal of identifying gaps and barriers to the safe deployment of hydrogen and fuel cell technologies. The Panel has conducted 22 meetings since 2003 at locations where there is significant interest and activities focused on hydrogen and fuel cells. The Panel engages code officials, project proponents and other stakeholders to discuss safety issues and barriers to the timely deployment of this technology. The discussion provides an opportunity for these groups to share their experiences and needs, and assists the HSP in understanding how to better align its initiatives and resources to meet those needs.

The HSP also continues to seek new ways to reach out to these groups. In 2014, Panel members met with participants in a hydrogen fueling station and repair garage project. The purpose of the meeting was to introduce participants to the Hydrogen Safety Panel and discuss their safety learnings from their recent project. The clear message from project participants was a need for more education and networking among those involved in plan reviews and inspections. Consistent with aligning initiatives to meet stakeholder needs, that message was integrated into planning activities for the Hydrogen Tools Portal discussed later in this paper.

Developing relationships with key industry organizations and state representatives has become an important new effort. In California, for example, the HSP is a participant on the California Green Team, a group led by the ombudsmen from the California governor's office to address barriers to the deployment of hydrogen fueling stations. Additionally, the expertise of the HSP is recognized in the state's Hydrogen Station Permitting Guidebook, a resource which suggests best practices for local and regional governments and station developers seeking to open (or in the process of opening) a hydrogen fueling station. [18] The guidebook provides an overview of the Panel and suggests that, "this panel can be consulted to review innovative projects and provide feedback and insights to both station developers and AHJs [authority having jurisdiction]." The HSP was also identified as a resource in Hawaii's draft implementation plan for deploying fuel cell vehicles.

Future state interactions are planned for the northeastern United States in support of initiatives to provide fueling stations from New Jersey through Massachusetts. The goal of these interactions is to reach state fire marshals and AHJs to raise awareness of the safety resources mentioned in this paper and help address barriers to the safe deployment of fuel cell vehicles. The Panel will continue to diligently reach out to make its resources available to other states as they begin developing a hydrogen infrastructure.

\subsection{REACHING USERS WITH TARGETED SAFETY KNOWLEDGE TOOLS}

The entire hydrogen community benefits if hydrogen safety-related knowledge is openly and broadly shared. One of the primary objectives of the DOE Fuel Cell Technologies Office is to develop and enable widespread sharing of safety-related information resources and lessons learned with first responders, AHJs, and other key stakeholders. [1] A number of safety knowledge tools focusing on safety event lessons learned, best practices and materials compatibility have been developed with emphasis on public accessibility for maximum value to a broad cross-section of users in the hydrogen and fuel cell community. A web-based portal was made available in 2015 that brings these tools and other hydrogen safety information together in one location. Additional information on the tools and portal is discussed below.

Hydrogen Lessons Learned $\left(\mathrm{H}_{2} \underline{\underline{L}} \underline{\mathrm{L}}\right)$

This database-driven website (http://h2tools.org/lessons), first developed in 2006, facilitates the sharing of lessons learned and other information gained from actual experiences using and working with hydrogen. The site is focused on characterizing hydrogen-related incidents and near-misses and the ensuing lessons learned. It currently contains 216 safety event records and enables those who work with hydrogen to share lessons learned from safety events at their facilities, with the goal of 
preventing similar events in the future. The target audience is anyone who works with or around hydrogen, in all types of settings (e.g., laboratories, fueling stations, commercial facilities, electric power plants, hydrogen delivery vehicles) and also includes those involved in the development of hydrogen-related codes and standards. [6] The site averages 19,000 visits per year.

\section{Hydrogen Safety Best Practices}

A wealth of knowledge and experience related to safe use and handling of hydrogen exists as a result of an extensive history in a wide variety of industrial and aerospace settings. To ensure the continued safe use of hydrogen, this knowledge must be passed on to the many new students, technicians and engineers who are engaging in the research, development, demonstration and deployment of hydrogen technologies, such as fuel cell vehicles and stationary fuel cells.

The Hydrogen Safety Best Practices Manual (http://h2tools.org/bestpractices) shares the benefits of extensive experience by providing suggestions and recommendations pertaining to the safe handling and use of hydrogen. The site is for anyone who works with or around hydrogen, in all types of settings (e.g., laboratories, fueling stations, warehousing and other commercial facilities). The Hydrogen Safety Best Practices manual was initiated in 2007 by the Pacific Northwest National Laboratory (PNNL) in collaboration with Los Alamos National Laboratory, the Hydrogen Safety Panel and other subject matter experts. Launching the online manual achieved a major DOE program milestone [2].

Collaborative tasks through the International Energy Agency Hydrogen Implementing Agreement work on hydrogen safety have played an important role in adding technical content to the $\mathrm{H}_{2} \mathrm{LL}$ as well as Hydrogen Safety Best Practices. Member countries for Task 19 (Hydrogen Safety) added safety event records to the former [6, 18]; a Task 22 (Fundamental and Applied Hydrogen Storage Materials Development) expert team developed new best practices content aimed at scientists and engineers working with reactive metal hydride storage materials. [19]

\section{Hydrogen Tools App}

The Hydrogen Tools application was developed in 2013 to bring a variety of hydrogen tools and web based content together in a single application for use on the current versions of Apple's iPad ${ }^{\circledR}$ and iPhone ${ }^{\circledR}$. The goal was to facilitate the sharing of hydrogen safety knowledge to a broader audience and in more mobile friendly format. The app features the lessons learned and best safety practices information discussed above. Conversion and NFPA separation distance calculators are also included along with an interactive safety planning checklist.

\section{Hydrogen Tools Portal}

In 2014, a diverse, 20-person team of stakeholders led by an experienced facilitator met to consider the question: What electronic safety tools would benefit the next phase of hydrogen and fuel cell commercialization? A hydrogen safety portal was identified as having the greatest potential for impact. A web-based tool intended to integrate existing safety resources into one central location would allow for a broader dissemination of safety information. [16]

To meet the need described above a new transformative tool, the Hydrogen Tools Portal (http://h2tools.org) was developed and launched publically in early 2015. It brings together and enhances the utility of a variety of tools and web-based content on the safety aspects of hydrogen and fuel cell technologies. The Portal is intended to help inform those tasked with designing, approving, or using systems and facilities, as well as those responding to incidents. [16]

There are significant benefits with this approach including easier access to find and search many safety resources from one location; focused content for specific user groups; a responsive design to allow the resources to be accessed from desktop and mobile devices; and an expandable format. 
Key features and benefits are summarized in Table 2.

Table 2. Key Features and Benefits of the Hydrogen Safety Portal

\begin{tabular}{|c|c|}
\hline Centralized Location & $\begin{array}{l}\text { Organizing a dozen hydrogen resources into one robust location and } \\
\text { capability for easily adding future content }\end{array}$ \\
\hline Focused Content & Tailored to the specialized needs of specific hydrogen user groups \\
\hline Responsive Design & $\begin{array}{l}\text { Enables hydrogen safety work across both desktop and mobile devices } \\
\text { (eliminating the need for a separate IOS app) }\end{array}$ \\
\hline Trusted Communities & $\begin{array}{l}\text { Fostered through social networking around hydrogen subject matter } \\
\text { expertise }\end{array}$ \\
\hline Expandable Format & Built with frequently requested future feature sets in mind \\
\hline
\end{tabular}

Another benefit may be less obvious - integrating safety resources to facilitate accessibility (and display) from a single, trustworthy source, can increase visibility and value. Combining the resources increases the population of potential users and the value to each through a "one-stop-shopping" approach. Viral or exponential growth is possible as the number of users is increased just as social networks tend to grow (http://www.reed.com/dpr/locus/gfn/reedslaw.html). Increased value through aggregated tools and information combined with the increase in users has the potential for rapid growth much more than individual, disparate, decentralized strategies do. The approach also provides the opportunity to reduce support costs by leveraging one infrastructure, technology, etc.

To increase the portal's effectiveness and benefits, eight user groups were considered during its design and development - AHJs, first responders, project proponents, operations/maintenance personnel, researchers/developers, insurers/risk managers, investors and the public. Community (discussion) groups are included in the Portal to encourage an exchange of learnings and experience among participants. This feature was specifically included to help address the need for "networking among those involved in plan reviews and inspections" (see Section 4.0).

Safety resources provided in the initial release of the Portal include:

- Hydrogen Lessons Learned

- Hydrogen Safety Best Practices

- Technical Reference for Hydrogen Compatibility of Materials

- Hydrogen Fuel Cell Standards

- Hydrogen Conversion Calculator

- Hydrogen Properties

- User Groups Community Discussions

- Hydrogen Safety Bibliographic Database

- Hydrogen Safety Panel

- Training for First Responders, Code Officials and Researchers

- Links to DOE-H2IQ, H2USA, California Fuel Cell Partnership

- Hydrogen Safety Videos

With its current list of resources, site features and design flexibility, the Hydrogen Tools Portal goes a long way to achieve DOE's goal of sharing safety knowledge and has the potential to become an ultimate hydrogen safety information dissemination tool. The approaches taken for the Portal are creating a rich environment for learning and applying safe practices. 
It is anticipated that additional resources will be added to the Portal in the future. The Portal was designed with this goal and is configured to support tools from government and nongovernment entities. Information owners always retain ownership and authority for their information and can update and make changes to their own information as necessary.

Future ideas for the Portal include developing a codes and standards guide. Such a tool could systematically lead a user through a series of topics to a particular set of requirements. When integrated into the Portal, requirements and supporting information such as best practices, related lessons learned, instructional videos and community discussion or feedback on related topics could be displayed side-by-side.

\section{Enhancing Confidence in Safety Resources}

Ensuring that a consistent set of accurate information is being provided on safety will help avoid unnecessary roadblocks and foster public confidence in the use of hydrogen. Unique communications branding can help promote safety resources that can be assets for enabling the widespread acceptance of hydrogen. The logo used for Hydrogen Safety Panel communications is illustrated in Figure 1. The consistent and appropriate use of branding will strengthen recognition of the Panel and its reputation as a safety resource, and will validate that information is coming from a reliable and credible source. The branding has also been implemented for the Hydrogen Tools Portal and National Hydrogen and Fuel Cell Emergency Response Training Resource.

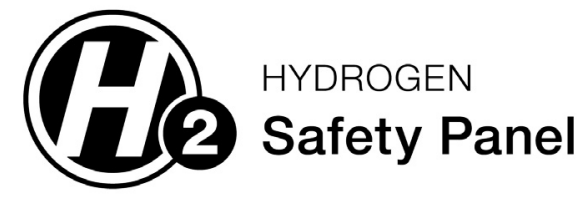

Figure 1. Example of communications branding: Hydrogen Safety Panel logo

\subsection{HYDROGEN-SPECIFIC TRAINING TOOLS FOR DIVERSE AUDIENCES}

The development of a number of hydrogen-specific training tools serving a diverse set of users has provided a valuable means for disseminating safety knowledge in a manner that complements other training programs and regimens.

Hydrogen Safety Training for Researchers (http://www.h2labsafety.org) provides a basic training through an interactive online four-hour course for laboratory researchers and other technical personnel who may be handling small amounts of hydrogen. Their need is for basic information on pressure, cryogenics, flammability, asphyxiation and other risks and precautions. A quiz is provided at the end of each of six modules. The course also features supplementary resources, such as a library section that includes publications, related links and a glossary of terms. $[6,20]$ The course was developed by the Lawrence Livermore National Laboratory and also represents a good example of a collaboration with the Hydrogen Safety Panel which served as a peer reviewer of the technical content.

Introduction to Hydrogen for Code Officials is another training course that provides an overview of hydrogen and fuel cell technologies, discusses how these technologies are used in real-world applications and references related codes and standards. This online training (http://www.hydrogen.energy.gov/code_official_training.html) facilitates the permitting and approval of demonstration and deployment projects across the nation. The course consists of four modules:

- Hydrogen and Fuel Cell Technology Basics

- Hydrogen and Fuel Cell Applications

- Hydrogen Fueling Stations

- Fuel Cell Facilities 
The curriculum helps users understand hydrogen technologies and properties in the context of generally adopted building and fire code requirements. For example, applicable codes and standards for permitting hydrogen technologies are cited in the Hydrogen Fueling Stations and Fuel Cell Facilities modules. Interactive animations provide information on current separation distances along with the codes and standards applicable to the design features illustrated in the animation. The course also features a library of relevant publications, related links and a glossary of terms used in the course. A short quiz follows each module and the user may print a "certificate of completion" with a tallied score.

The online course was developed in conjunction with a series of workshops on hydrogen codes and standards that target project developers and code officials. The workshops have been conducted at key geographic locations where hydrogen projects were planned. Five hundred attendees from seven states have completed the course to date.

First responder training continues to be an integral part of the DOE-funded hydrogen safety work. A properly trained first responder community is critical to the successful introduction of hydrogen fuel cell applications and their transformation in how we use energy. Three training resources serve a specific need in different ways. An online awareness-level course, Introduction to Hydrogen Safety for First Responders, was launched in January 2007 (http://hydrogen.pnl.gov/FirstResponders/). [5] Its development and review engaged over 100 subject matter experts from the hydrogen and emergency response communities and the training continues to serve 200-300 hundred visitors monthly.

PNNL developed an operations-level one-day course combining a classroom curriculum and live-fire exercises and engaging the California Fuel Cell Partnership (CaFCP), the Volpentest HAMMER Federal Training Center and Kidde Fire Trainers in this effort. [21] The latter designed and built a vehicle burn prop/trailer for transport to various locations. As part of this collaboration, the Hydrogen Safety Panel served to review the burn prop design and operational safety plan. The course was first delivered in 2009 and over 1,000 attendees have been trained in Washington, California and Hawaii.

Hydrogen and fuel cell-related first responder training experiences suggested the need to develop a national emergency response training resource as a consistent source of accurate information and current knowledge. The nationally-focused training template (http://www.h2tools.org/fr/nt/), available as a free download slide package (see sample slide, Figure 2), serves that purpose as a resource and guide for the delivery of a variety of training regimens to various audiences. In this manner, it is adaptable to the presentation styles of training organizations and meant to complement extensive training programs already in place. 


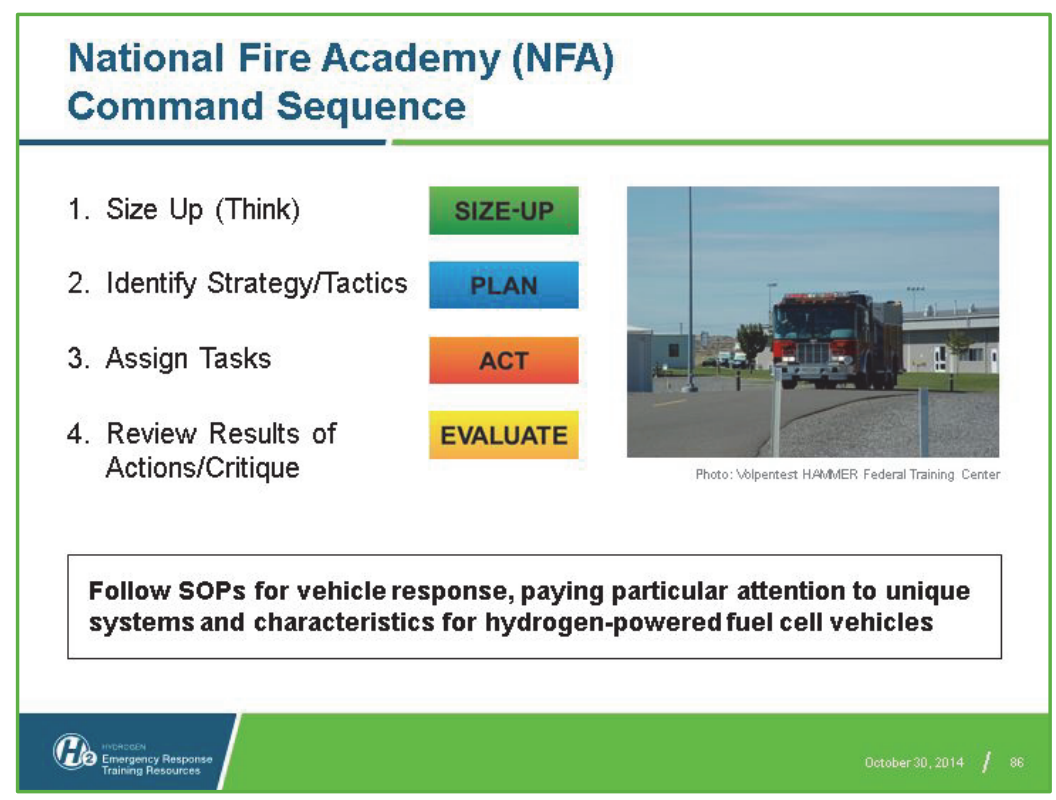

Figure 2 Sample slide from the National Hydrogen and Fuel Cell Emergency Response Training Resource

With a focus on future activities, PNNL and the CaFCP convened a group of first responder trainers, facility and equipment providers and other interested persons in 2015 to consider what materials and delivery methods are best suited to enhancing the first responder learning outcomes. Recommendations were provided to serve three purposes: (1) identify enhancements for the existing training resources, (2) recommend new impactful resources and materials that should be added to the training portfolio, and (3) provide guidelines that can be used to inform the direction of future training development efforts. Results suggest that improved images and videos, new props and consideration of virtual reality tools could help improve the instructional quality and potential reach of first responder hydrogen safety training resources in a cost effective manner.

\subsection{CONCLUDING THOUGHTS}

The comprehensive safety management program and diverse project portfolio discussed in this paper enables the Safety, Codes and Standards sub-program to help overcome institutional and market challenges for hydrogen and fuel cell technologies. The technical barriers associated with these challenges, and discussed in detail in the DOE MYRD\&D Plan [2], are noted as follows:

- Safety data and information: limited access and availability

- Availability and affordability of insurance

- Safety is not always treated as a continuous process

- Lack of hydrogen knowledge by AHJs

- Lack of hydrogen training materials and facilities for emergency responders

- Insufficient technical data to revise standards

- Lack of consistency in training of officials

The progress demonstrated through specific initiatives and collaborations is helping to reduce these barriers. As noted in the 2014 Annual Merit Review and Peer Evaluation Report [22]: "The project very effectively takes on Hydrogen and Fuel Cells Program goals and objectives and puts real-time solutions directly into the hands of those who are deploying hydrogen technologies." 
The engagement of a broad cross-section of stakeholders is helping the Hydrogen Safety Panel and other subject matter experts to apply knowledge gained to further the progress achieved. Ensuring that the safety knowledge resources developed and discussed in this paper are kept current and relevant to their intended purpose will be critical to sustaining such progress to meet the goals and objectives of the hydrogen and fuel cell technologies program as a whole.

\subsection{ACKNOWLEDGMENTS}

The authors wish to thank the U.S. Department of Energy's Fuel Cell Technologies Office (Sunita Satyapal, Director) for their support of this work. The encouragement, interest and support by many DOE staff have been instrumental in the successful conduct of these initiatives. The collaborations with other DOE national laboratories engaged in the work of Safety, Codes and Standards subprogram is also gratefully acknowledged.

\subsection{REFERENCES}

1. U.S. Department of Energy, "Fuel Cell Technologies Office Multi-Year Research, Development and Demonstration (MYRD\&D) Plan," Executive Summary, July 2012. http://energy.gov/sites/prod/files/2014/03/f9/exec_sum.pdf

2. U.S. Department of Energy, "Fuel Cell Technologies Office Multi-Year Research, Development and Demonstration (MYRD\&D) Plan," Section 3.7 - Hydrogen Safety Codes and Standards, July 2013. http://energy.gov/sites/prod/files/2014/03/f10/safety codes.pdf

3. Weiner, S.C., Kinzey, B. and Skolnik, E.G., "Hydrogen Safety Review Panel: Shaping Safety Awareness," PNNL-15055, 20 ${ }^{\text {th }}$ Annual Center for Chemical Process Safety International Conference, Atlanta, GA, April 12, 2005.

4. Weiner, S.C. and Barilo, N.F., "Hydrogen Safety Panel: Shaping Safety Awareness and Practice," PNNL-SA-61902, 2008 Mary Kay O’Connor Process Safety Center International Symposium, College Station, TX, October 28-29, 2008.

5. Fassbender, L.L., Akers, B.M. and Cooper, C, "Introduction to Hydrogen Safety for First Responders," Firehouse ${ }^{\circledR}$, August 2007, pp 158-159.

6. Weiner, S.C., Fassbender, L.L., Blake, C., Aceves, S., Somerday, B.P. and Ruiz, A., "Web-Based Resources Enhance Hydrogen Safety Knowledge," PNNL-SA-82812, International Journal of Hydrogen Energy, Volume 38, Issue 18, June 2013, pp 7583-7593.

7. Weiner, S.C., Kallman, R.A., Ruiz, A. and Schneider, J.M., "Hydrogen Safety: From Policies to Plans to Practices," Paper 100068, PNNL-SA-45632, International Conference on Hydrogen Safety, Pisa, Italy, September 8-10, 2005.

8. DOE Fuel Cell Technologies Office, "Safety Planning Guidance for Hydrogen and Fuel Cell Projects" http://energy.gov/sites/prod/files/2014/03/f10/safety guidance.pdf, April 2010.

9. Weiner, S.C., "From Laboratory to Demonstration: Safety Practices and Lessons Learned," PNNL-SA-50930, First European Summer School Hydrogen Safety (ESSHS), University of Ulster, Belfast, UK, August, 2006. http://www.hysafe.org/science/eAcademy/docs/1stesshs/ presentations/ESSHS_Weiner_8-06.pdf

10. Weiner, S.C., "Hydrogen Safety Panel," PNNL-SA-86512, Hydrogen and Fuel Cells Program Annual Merit Review and Peer Evaluation Meeting, Arlington, VA, May 15, 2012. http://www.hydrogen.energy.gov/pdfs/review12/scs008 weiner_2012_o.pdf

11. Weiner, S.C. and N.F. Barilo, "Hydrogen Safety Panel Review of DOE Fuel Cell Projects," PNNL-22075, December 18, 2012.

12. Barilo, N.F. and Weiner, S.C., "Deploying Fuel Cell Systems: What Have We Learned?" PNNLSA-94975, International Conference on Hydrogen Safety, Brussels, Belgium, September 9, 2013.

13. Communication from Mitch Ewan, Hawaii Natural Energy Institute, University of Hawaii, 2012. 
14. Barilo, N.F., "Safety of Hydrogen Systems Installed in Outdoor Enclosures," PNNL-22960, November 2013.

15. Barilo, N.F. and Weiner, S.C., "Final Report: Hydrogen Safety Panel Review of DOE Fuel Cell Projects" PNNL-22075, Pacific Northwest National Laboratory, Richland, WA, August 2013.

16. Barilo, N.F., "Electronic Safety Resource Tools - Supporting Hydrogen and Fuel Cell Commercialization, PNNL-23704, Pacific Northwest National Laboratory, September 2014.

17. Hydrogen Safety Panel. 2016, "Hydrogen Equipment Certification Guide - Listing, Labeling and Approval Considerations." Available at: https://h2tools.org/sites/default/files/Hydrogen_Equipment_Certification_Guide 20151210.zip.

18. GO-Biz. 2015, "Zero-Emission Vehicles in California: Hydrogen Station Permitting Guidebook," California Governor's Office of Business and Economic Development. Sacramento, CA. Available at: https://www.business.ca.gov/Programs/Permits/HydrogenStationPermitting.aspx.

19. Weiner, S.C. and Blake, C.W., "Safety Knowledge Tools Enhanced by International Collaboration," A White Paper of the International Energy Agency Hydrogen Implementing Agreement Task 19 - Hydrogen Safety, PNNL-19901, October 18, 2010.

20. Aceves, S.M., Espinosa-Loza, F., Petitpas, G., Ross, T.O. and Switzer, V.A., "Hydrogen Safety Training for Researchers and Technical Personnel," International Conference on Hydrogen Safety, San Francisco, CA, September 12-14, 2011.

21. Elmore, M.R., Fassbender, L.L., Hamilton, J.J. and Weiner, S.C., "Hydrogen Emergency Response Training for First Responders," PNNL-SA-79009/82560, International Conference on Hydrogen Safety, San Francisco, CA, September 12-14, 2011.

22. DOE Hydrogen and Fuel Cells Program: 2014 Annual Merit Review and Peer Evaluation Report, DOE/GO-102014-4503, October 2014. 